\title{
O PRO-ÁLCOOL E ALGUMAS RELAÇÕES CTS CONCEBIDAS POR ALUNOS DE 6ä SÉRIE DO ENSINO FUND AMENTAL.
}

\author{
Elenise C ristina Pires de Andrade ${ }^{1}$ \\ Luiz M arcelo de Carvalho ${ }^{2}$
}

\begin{abstract}
Resumo: A crescente degradação do meio ambiente e o reconhecimento, por parte da sociedade contemporânea, da existência de problemas considerados críticos, acentuadamente a questão energética, intensifica a preocupação em incorporar nas atividades de ensino aspectos da relação do ser humano com 0 ambiente. A necessidade de abordar, durante atividades de ensino de ciências, questões relacionadas com a dimensão val orativa e aspectos da relação entre ciência, tecnologia e sociedade passa a ser reconhecida tanto por educadores de maneira geral quanto por especialistas da área, de maneira particular. 0 movimento Ciência, Tecnologia e Sociedade (CTS) como um conjunto de propostas para 0 ensino de ciências é uma conseqüência concreta desta tendência. No caso do Brasil são poucas as pesquisas em ensino de ciências que exploram essa possibilidade e são poucas as experiências em termos de trabal hos em sala de aula que abordam esta questão.

Este trabal ho, realizado entre maio e novembro de 1996, sistematiza os dados coletados em uma classe de 6a série do ensino fundamental que teve como tema de estudos o "Projeto Pro-Álcool". Foi planejado e desenvolvido um conjunto de atividades, utilizando-se de um número bastante diversificado de procedimentos didáticos.

O s resultados de pesquisa indicam que, um trabalho que ofereça aos alunos oportunidades de discussões e reflexões, a partir de procedimentos e material didático diversificado e rico em termos de solicitações e propostas aos alunos, pode promover a incorporação, em sala de aula, de diferentes dimensões relacionadas com a ciência, tecnologia, sociedade e ambiente.
\end{abstract}

Unitermos: Pro-Álcool; meio ambiente; Ciência, Tecnologia e Sociedade; Ensino de Ciências; Educação Ambiental

\begin{abstract}
The increasing environmental degradation and the recognition of critical problems nowadays, mainly en ergetic questions, have intensified the concerning by researchers and sci ence teachersin order to consider in science teaching activities on aspects related to interactions between human beings and the environment. The necessity of incorporating questions related to values and the interactions between science, technology and society in sci ence teaching activities began to be recognized as crucial by science teachers and experts. An objective resulting of this tendency is to approach Science, Technology and Society (ST S) as a whole of proposals to science teaching. In Brazil there are few researches in science teaching trying to explore theses pos sibilities and few dassroom experiences dealing with this approach.

This research wascarried out from may to $\mathrm{N}$ ovember, 1996. It systematically collected data in one class of 12 years olds Brazil's Fundamental School (from 7 to 14 year olds). A discussion with pupils of a national project installed in Brazil in 1975 to product ethanol as an alternative source of energy for cars was promoted. A complete set of activities applying diversfied teaching procedures and pedagogic materials were planned and carried out.

The results indicate that, if we can offer to pupils opportunities for discussing and reflecting, through diversified teaching procedures and a rich environment in terms of pupils proposals and questioning, we can bring to classrooms different dimensions related to science, technology, society and environment, from specific examples close to pupils, about science and technology development.
\end{abstract}

Keywords: Pró-Álcool; Environment; Science, Technology and Society; Science Teaching; Environmental Education

\footnotetext{
${ }^{1}$ M estre em Educação pela U niversidade Estadual de Campinas e Professora da Rede Pública de Ensino do Estado de São Paulo, Brasil.

2 Professor Assistente Doutor do Departamento de Educação do Instituto de Biociências da Universidade Estadual Paulista, Câmpus de Rio Claro, São Paulo, Brasil. (e-mail: Imarcelo@rc.unesp.br)
} 


\section{Introdução}

$\mathrm{N}$ as últimas décadas, o valor e a importância de políticas educacionais que garantam a alfabetização, no seu sentido mais amplo, têm sido reconhecidos por diferentes setores da sociedade. Acompanhando essa tendência mais geral, tem-se buscado novas perspectivas para o Ensino de Ciências e questionado o seu papel em uma sociedade com alto grau de influência da Ciência e da Tecnologia.

Procurando contextualizar as tendências sobre as políticas educacionais com relação ao Ensino de Ciências no Brasil, Krasilchik (1987) identifica que o grande objetivo desse ensino, no período de 1950-60, era transmitir informações, sem a preocupação nos projetos curriculares com questões que relacionassem ciência com o contexto econômico, social e político no qual a mesma é produzida. Além disso, também eram muito raras as propostas de discussões sobre Tecnologia, suas aplicações práticas e 0 impacto que 0 uso de determinados recursos tecnológicos causavam no ambiente.

$\mathrm{N}$ a década de 60 as propostas curriculares sofreram al gumas transformações quanto à estrutura, incorporando um objetivo muito específico, qual seja: (...) permitir a vivência do método científico como necessário à formação do cidadão (Krasilchik, 1987). 0 antigo enfoque sobre a pura transmissão de conhecimento cedeu lugar à investigação real izada pelo aluno, de acordo com determinados procedimentos estabelecidos a priori. Acreditava-se, assim, que a vivência do método científico fosse suficiente para melhor compreender a natureza da C iência; tentava-se, desse modo, considerar a Ciência como algo mais que um simples conjunto de conhecimentos.

$\mathrm{N}$ a década seguinte, com a intensificação da degradação ambiental e agravamento de outras crises, como por exemplo a energética, novas questões foram colocadas pela sociedade. C resceu entre os educadores, a preocupação com incorporar às atividades de ensino aspectos abrangendo a relação do ser humano com 0 ambiente, objetivando abordar: a depredação provocada pelo homem sobre os componentes da biosfera, a significação e o papel do conhecimento científico e tecnológico na destruição da biosociodiversidade ea necessidade de incorporação de valores e objetivos relativos aos aspectos sociais, econômicos e políticos no processo de produção do conhecimento científico e tecnológico.

No Brasil, mais especificamente no Estado de São Paulo, uma proposta curricular para o Ensino de Ciências para as primeiras oito séries do ensino de 1ำ grau foi apresentada no G uia Curricular da Secretaria da Educação do Estado de São Paulo (São Paulo, 1975), propondo discussões, ainda muito iniciais, acerca da produção científica e tecnológica, assim como das interferências da $C \& T$ nas ações humanas.

No final da década de 80, a equipe técnica de Ciências da CEN $P^{3}$, juntamente com alguns professores da rede pública paulista construíram um outro documento oficial para o Ensino de Ciências, propondo discussões ainda mais amplas sobre a tríade Ciência, Tecnologia e Sociedade (CTS). 0 documento, ainda hoje oficial, ou seja, a Proposta Curricular para o Ensino de Ciências e Programas de Saúde para o Primeiro Grau do Estado de São Paulo (1988), dentre outros pressupostos, afirma que:

(...) É preciso que os alunos adquiram uma compreensão mais realista do significado e utilidade da Ciência e da Tecnologia e de suas relações com a Sociedade

Para isso, é necessário que se caracterize a Ciência como uma atividade não neutra, isto é, com vinculações políticas, sociais, econômicas e culturais na sua produção;

${ }^{3}$ Coordenadoria de Estudos e $\mathrm{N}$ ormas Pedagógicas 
historicamente determinada; inacabada, no sentido de que não há verdades absolutas, inquestionáveis e imutáveis, fruto de produção coletiva e não unicamente de cérebros privilegiados. (grifo do original, p.18)

Com relação às atuais diretrizes nacionais, o volume dos Parâmetros Curriculares $\mathrm{N}$ acionais voltados ao ensino das $\mathrm{C}$ iências $\mathrm{N}$ aturais para as quatro últimas séries do ensino fundamental (Brasil, 1998) seleciona, entre os eixos temáticos propostos ${ }^{4}$ para os conteúdos a serem trabalhados nessa abordagem, o tema Tecnologia e Sociedade. N esse documento é proposto que o Ensino de Ciências seja realizado com o (...) enfoque das relações entre Ciência, Tecnol ogia e Sociedade, no presente e no passado, no Brasil e no mundo, em vários contextos culturais, considerando-se as alterações que 0 acesso e o uso da Tecnol ogia promovem no meio social e na realidade econômica. (Brasil, 1998, p.48).

Atualmente, pode-se notar que CTS tornou-se uma importante tendência no Ensino de Ciências, podendo ser entendida como uma nova "ênfase curricular". Segundo Roberts (1982), esse enfoque curricular teria, como objetivo inicial, uma diferenciação entre Ciência eTecnologia. Em seguida distinguir-se-iam os aspectos científico-tecnológicos daqueles relacionados aos valores que envolvem a tomada de decisões no campo pessoal e político, referindo-se, então, às dimensões sociais, econômicas e políticas do processo de construção da Ciência e da Tecnologia.

Apesar do aparato fornecido pelas orientações presentes em vários documentos curriculares oficiais, podemos notar que a escola continua constantemente apresentando a Ciência como um conhecimento finito, fruto de um processo que ocorre à parte da Sociedade. Essa postura possibilita freqüentemente que o aluno conceba a Ciência e a Tecnologia como conhecimentos fixos e imutáveis, além de mitificar os objetivos de seus respectivos processos de desenvolvimento, atribuindo-Ihes um caráter inerente de benefício para toda a humanidade.

Para questionar essa concepção, a escola, instituição inserida e ativa na construção da sociedade, deveria representar o local em que os futuros cidadãos entram em contato com as relações entre Ciência, Tecnologia e Sociedade. N ota-se, no entanto, que, apesar do esforço dos educadores na tentativa de mudança, percebemos que a escola continua apresentando a Ciência como una, sem dissensões, sem divergências, sem competições internas, sem disputa (Trivelato, 1994). Além disso, quando os alunos e os demais participantes do ensino das disciplinas científicas identificam alguma relação entre a Ciência e a Sociedade, ela parece, geralmente, fundamentar-se em uma visão de que a dependência da Sociedade em relação à Tecnologia é um aspecto natural. Parece não existir, por parte dessas pessoas, um reconhecimento adequado no que concerne à existência de intrínsecas e complexas relações tanto de dependência, como também de influência entre a Ciência, a Tecnologia e a Sociedade.

Portanto, parecenos imprescindível o desenvolvimento de pesquisas que revelem aos profissionais da área do Ensino de Ciências caminhos para o desenvolvimento de atividades que abordem questões referentes à conexão entre Ciência, Tecnologia e Sociedade. Tais questões mostram-se ainda mais rel evantes se consideradas as características do cenário da vida atual, quando os mais diferentes interesses e valores fundamentam a construção e legitimação do conhecimento científico e tecnológico.

A possibilidade para o desenvolvimento de um trabalho fundamentado nesses pressupostos surgiu a partir de atividades de Ensino de Ciências, que vinham sendo desenvolvidas com uma 6a série do Ensino Fundamental em uma escola pública do Estado de São Paulo.

${ }^{4}$ Ao total os PCN apresentam quatro eixos temáticos: Terra e Universo, Vida e Ambiente, Ser Humano e Saúde e Tecnologia e Sociedade. 
Considerando os temas propostos para essa série, segundo a versão de $1991^{5}$ da Proposta Curricular para o Ensino de Ciências e Programas de Saúde (São Paulo, 1991), escolhemos o Projeto Pro-álcool como tema inicial, a partir do qual discutimos com os alunos além dos conceitos científicos tais como a dinâmica dos ecossistemas e a interferência humana nestes, outros, como, por exemplo, a influência de interesses econômicos e culturais nas atividades humanas e possibilidades de controle dos impactos ambientais.

0 planejamento, a execução e a avaliação pautaram-se nos seguintes objetivos:

1. Identificar as concepções presentes entre os al unos quanto às relações CTS.

2. I dentificar o posicionamento dos alunos frente às questões de impacto causadas pelo desenvolvimento científico-tecnológico na forma de organização da Sociedade.

3. O ferecer subsídios e propostas de ensino que tenham como objetivo a incorporação de questões relativas a CTS no Ensino Fundamental.

Tendo como orientação geral as considerações já apresentadas, algumas questões mais específicas direcionaram esta pesquisa tanto no que diz respeito à coleta de dados como a sua análise e interpretação, como segue: os al unos de 6a série do Ensino Fundamental identificariam, claramente, a existência de uma recíproca e complexa relação entre Ciência, Tecnol ogia e Soci edade? Q ual o posicionamento dos alunos frente às questões de impactos causados pelo desenvolvimento científico e tecnológico na forma de organização da Sociedade? D e que forma questões dessa natureza podem ser tratadas em atividades de Ensino de Ciências na escola fundamental, incorporando-as ao trabalho desenvolvido pelo professor?

\section{Procedimentos}

Para desenvolvimento das atividades de coleta, análise e interpretação dos dados, foram utilizados procedimentos de pesquisa vinculados ao movimento que se convencionou chamar de "professor-pesquisador" (teacher as researcher) (O berg and M cC utcheon, 1990). Essa perspectiva, como movimento em termos de pesquisa, é uma conseqüência da pesquisaação educacional, que tem como objetivo (...) reduzir a distância entre teorias sociais e práticas sociais. (O berg and M cC utcheon,1990).

M cC utcheon and Jung (1990), em uma tentativa de caracterizar essa abordagem na pesquisa educacional, apontam, a partir de vários outros pesquisadores, al guns aspectos básicos desses trabalhos: investigações sistemáticas, coletivas, colaborativas, auto-reflexivas, críticas e que levam em conta todos os participantes da investigação. 0 objetivo de tais procedimentos é a busca para uma melhor compreensão da prática e sua articulação com a teoria, para aperfeiçoamento da primeira por meio de estudos sistemáticos que envolvam tanto a própria prática quanto a conseqüente teoria que a fundamenta. D esse modo, espera-se alcançar 0 desenvolvimento de habilidades que facilitem um pensamento mais crítico, metodologicamente mais fundamentado e sócio-politicamente mais colaborativo.

O s dados foram coletados durante as atividades de ensino. Este procedimento de pesquisa apresenta aspectos altamente positivos, por proporcionar a incorporação de dimensões mais gerais do complexo processo de ensino-aprendizagem, além de identificar o professor

\footnotetext{
${ }^{5}$ A versão desse documento editado e publicado em 1991 difere da versão mais antiga publicada em 1988, principalmente no que concerne à di stribuição e apresentação das sugestões programáticas. N esse documento mais recente tais sugestões são divididas em séries espeć́ficas e, na versão de 1988, essa divisão acontece para ciclos de séries. No caso especí-

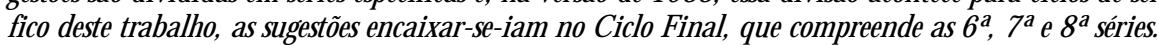


como agente ativo, fundamental e indispensável para uma melhor compreensão do trabalho pedagógico.

Escolhemos, assim, uma das possibilidades apresentadas por Yager (1993), qual seja, a apresentação de uma situação inicial para que, a partir dela, planejássemos e executássemos atividades que auxiliassem os al unos a identificar a utilidade e a validade, não somente científica, mas também política, econômica e cultural, dos conceitos e processos envolvidos nas questões relacionadas à CTS.

Selecionamos, para o desenvolvimento deste trabalho, o "Programa $\mathrm{N}$ acional do Álcool - Proálcool", instituído no Brasil pelo Decreto no 76.593 de 14/11/1975, que apresentava como objetivos básicos: a expansão da produção de etanol; a redução das disparidades regionais de renda; 0 aumento da renda interna, com melhoria de sua distribuição; 0 bom aproveitamento das principais matérias-primas e a implementação de destilarias de álcool etílico.

Além desses objetivos e dos aspectos oficiais que o Pro-álcool apresentou, foram também envolvidos em sua implementação diversas questões ambientais, bastante adequados para o tratamento das temáticas em questão. M ais um fator positivo do Pro-álcool relacionase a um aspecto geográfico, pois a cidade onde a pesquisa foi desenvolvida - Limeira, SP pertence a uma das maiores regiões agroindustriais do Estado de São Paulo, notadamente a indústria canavieira, abrangendo a U sina I racema, no município de I racemápolis; U sina São João, no município de Araras; U sina Ester, no município de Cosmópolis; uma unidade de refinação de açúcar da Companhia União dos Refinadores de Açúcar e Café, sediada em Limeira.

As atividades para a coleta dos dados foram desenvolvidas em uma classe de 6 a série do Ensino Fundamental de uma escola localizada em um bairro com características básicas de "estrato médio" em termos de condições sócio-econômicas e de condições de infra-estrutura urbana. A população do bairro é composta majoritariamente de operários e a escola é a única nas proximidades a oferecer ensino de 5 a à 8 a séries do Ensino Fundamental, de modo que há grandes dificuldades para al unos conseguirem vagas nessas séries; as classes são extremamente numerosas, com aproximadamente 50 alunos no início do ano letivo.

0 primeiro e talvez um dos mais importantes recursos utilizados para o acompanhamento das atividades e o registro de dados é o que chamamos de ficha ou diário de observação, instrumento que nos permitiu o registro imediato de todas as nossas observações, incluindo as sensações, percepções, atitudes e frases dos alunos, além de avaliações espontâneas, comentários, etc. feitos pelos alunos, após cada atividade.

O utro recurso para obtenção de dados foi todo e qualquer material produzido pelos alunos durante as atividades. Esse material, antes de ser a eles devolvido, era minuciosamente analisado e os dados de interesse imediato para a pesquisa, registrados.

\section{D escrição das atividades desenvolvidas}

A primeira etapa da pesquisa constituiu-se da elaboração de um plano de ensino para orientar os trabalhos, de forma que, não foi visto como definitivo, mas como um instrumento flexível a ser ajustado conforme o desenvolvimento das atividades com os alunos.

Apenas como exemplo dessa flexibilidade podemos citar que, embora tivéssemos previsto oito aulas para o desenvolvimento de todo o projeto, o mesmo envolveu 14 aulas, compreendendo os meses de maio a novembro de 1996. O s procedimentos iniciais e os objetivos foram seguidos, mas acrescentaram-se atividades extras, que nos pareceram necessárias após releitura do plano de ensino original e o desenvolvimento dos trabal hos em sala de aula. 
A elaboração do material didático foi fundamentada em um texto de apoio produzido com o auxílio de bibliografia especializada tanto no que concerne aos aspectos científicos do desenvolvimento do projeto, quanto aos que envolvem os profundos impactos ambientais e sociais que o Pro-álcool causou à sociedade brasileira, inclusive à limeirense. Tal elaboração ocorreu concomitantemente com o desenvolvimento das atividades, juntamente com alguns redirecionamentos realizados no plano de ensino, quando julgávamos necessário.

As atividades relacionadas à discussão do Pro-álcool foram desenvolvidas alternadamente com aquelas que abordavam outras atividades já previstas para o desenvolvimento de temas/conteúdos planejados inicialmente para aquela classe. A decisão foi tomada para evitar uma sobrecarga de atividades propostas aos alunos, ao mesmo tempo que permitia ao professor-pesquisador a possibilidade de avaliação e redirecionamento, caso necessário, dos trabalhos previstos.

\section{Q uadro 1- Atividades referentes com aspectos da relação Ciência, Tecnologia e Sociedade (em especial ao projeto Pro-álcool) desenvolvidas com alunos de 6a série de uma escola pública de ensino fundamental no município de Limeira - SP.}

\begin{tabular}{|c|c|c|}
\hline Aula & Atividades desenvolvidas & Recursos didáticos \\
\hline $1 \underline{a}$ e $2 \underline{a}$ & $\begin{aligned} & \text { Levantamento e discussão de } \\
& \text { exemplos de degradação } \\
& \text { ambiental observados pelos al unos. } \\
\text { ₹ } & \text { M ontagem de tabela (realizada } \\
& \text { pelos alunos) resultante das } \\
& \text { observações dos alunos no trajeto } \\
& \text { deles entre a escola e a residência. }\end{aligned}$ & \\
\hline $3 \underline{a}$ & $\begin{aligned} \text { D esenvolvimento por meio de } \\
\text { aulas expositivas dos conceitos de } \\
\text { caloria e energia, envolvendo, além } \\
\text { dos aspectos físicos e químicos, } \\
\text { também os aspectos ambientais. }\end{aligned}$ & $\begin{aligned} &= \text { Textos preparados pela professora } \\
& \text { e entregue aos alunos. } \\
&= \text { Q uestões apresentadas aos alunos } \\
& \text { para serem discutidas. }\end{aligned}$ \\
\hline $4 \underline{a}$ & $\begin{aligned} \text { 乏 } & \text { Interpretação e discussão com os } \\
& \text { alunos das músicas "Cio da Terra" } \\
& \text { (M ilton N ascimento) e "Sítio do } \\
& \text { Pica-pau Amarelo" (Gilberto Gil). } \\
\text { \& } & \text { Identificação das idéias iniciais dos } \\
& \text { alunos quanto ao significado da } \\
& \text { palavra "Tecnologia". }\end{aligned}$ & $\begin{aligned} \text { - Texto e apresentação das músicas } \\
\text { para o tratamento de questões que } \\
\text { envolvessem a utilização e } \\
\text { conservação dos solos e produtos } \\
\text { agrícolas, além da discussão do } \\
\text { processo tecnológico envolvido. } \\
\text { = } \\
\text { Questões sobre as letras das } \\
\text { músicas para discussão, em grupo, } \\
\text { do tema acima citado }\end{aligned}$ \\
\hline
\end{tabular}




\begin{tabular}{|c|c|c|}
\hline $5 \underline{a}$ & $\begin{array}{l}\text { I Identificação pelos alunos das } \\
\text { idéias e dos conhecimentos das } \\
\text { pessoas da comunidade acerca do } \\
\text { processo de produção de álcool } \\
\text { etílico a partir da fermentação do } \\
\text { caldo de cana. A coleta desses } \\
\text { dados deu-se durante as férias de } \\
\text { julho. }\end{array}$ & $\begin{aligned}= & \text { Aproveitando as questões utilizadas } \\
& \text { na discussão e interpretação das } \\
& \text { músicas, montou-se um } \\
& \text { questionário com três questões } \\
& \text { para ser utilizado na pesquisa } \\
& \text { junto à comunidade. } \\
= & \text { Explicação dos critérios que seriam } \\
& \text { seguidos na escolha dos vizinhos a } \\
& \text { serem entrevistados. }\end{aligned}$ \\
\hline 6a e 7a & $\begin{aligned}= & \text { A presentação e discussão dos } \\
& \text { resultados de Pesquisa de } 0 \text { pinião. } \\
\leqslant & \text { C ategorização dos resultados da } \\
& \text { enquete obtidos pelos alunos e } \\
& \text { conseqüente discussão dos mesmos. }\end{aligned}$ & $\begin{aligned}= & \text { Cartazes com identificação das } \\
& \text { idéias e os conhecimentos das } \\
& \text { pessoas da comunidade. }\end{aligned}$ \\
\hline $8 \underline{a}$ & $\begin{array}{l}\text { D esenvolvimento por meio de } \\
\text { aulas expositivas dos conceitos de } \\
\text { fermentação e da utilização } \\
\text { econômica desses conhecimentos: } \\
\text { queijo, vinagre, bebidas alcoólicas, } \\
\text { álcool. }\end{array}$ & $\begin{array}{l}\text { = Q uestões formuladas pela } \\
\text { professora para discussão entre os } \\
\text { alunos da importância sob vários } \\
\text { aspectos do processo de } \\
\text { fermentação. }\end{array}$ \\
\hline $9 \underline{a}$ e $10^{a}$ & $\begin{array}{l}\text { Estudo dirigido que tentou retratar } \\
\text { as alterações sociais, políticas, } \\
\text { econômicas e ambientais ocorridas } \\
\text { com a implantação do Pro-álcool; } \\
\text { papel da participação social nas } \\
\text { políticas de desenvolvimento } \\
\text { científico e tecnológico. }\end{array}$ & $\begin{aligned}= & \text { Estudo dirigido: } 0 \text { Pro-álcool e a } \\
& \text { cultura da cana-de-açúcar. } \\
\text { = } & \text { Discussão com os alunos a partir } \\
& \text { da leitura de um texto e análise de } \\
& \text { tabelas, gráficos e mapas. }\end{aligned}$ \\
\hline $11^{\mathrm{a}}$ e $12^{\mathrm{a}}$ & $\begin{array}{l}\text { Abordagem de temas relativos ao } \\
\text { panorama brasileiro e mundial, } \\
\text { relativos à década de } 70 \text { na } \\
\text { implantação do Pro-álcool. }\end{array}$ & $\begin{array}{l}\text { E Estudo dirigido a partir de um } \\
\text { vídeo do programa G lobo } \\
\text { Repórter da TV G lobo } \\
\text { "O açúcar e o álcool". }\end{array}$ \\
\hline $13^{a}$ e e 14a & $\begin{aligned} \text { D iscussão, em pequenos grupos, a } \\
\text { respeito de considerações de al guns } \\
\text { cientistas brasileiros acerca do } \\
\text { desenvolvimento científico e } \\
\text { tecnológico e suas relações com as } \\
\text { ações governamentais. } \\
\text { = Discussão e pedido de redação sobre } \\
\text { o desenvolvimento tecnológico } \\
\text { brasileiro e a existência de técnicos } \\
\text { especializados nas U niversidades e } \\
\text { Institutos brasileiros. }\end{aligned}$ & $\begin{array}{l}\text { = Apresentação de dois institutos de } \\
\text { pesquisa: o IPT em São Paulo e } \\
\text { Fraunhofer na Alemanha, sob a } \\
\text { forma de textos em cartões } \\
\text { coloridos. }\end{array}$ \\
\hline
\end{tabular}




\section{Resultados e discussões}

Com o objetivo de melhor analisar as idéias e as concepções de 10.800 estudantes a respeito de relações CTS no Canadá, Aikenhead, Fleming e Ryan (1987) propuseram uma nova metodologia para pesquisas que envolvessem a identificação de concepções de um grande número de pessoas: o VOSTS (Views on Science-Technology-Society) ${ }^{6}$. U ma das maiores vantagens desse instrumento, segundo seus autores, seria a possibilidade de obtenção de respostas mais abertas, menos diretivas que as obtidas com testes de múltipla escolha.

A partir desse mesmo instrumento, Aikenhead e Ryan (1992) propuseram uma remodel ação do V O ST S para abrigar diferentes ênfases ou especificidades que se desejasse pesquisar, formulando oito diferentes categorias para análise?. Com base nessa proposta e após uma análise preliminar dos dados coletados, elaboramos um quadro para a categorização, descrita a seguir, das respostas dos al unos às diferentes situações propostas na pesquisa.

\section{Q uadro 2 - C ategorias e subcategorias utilizadas para sistematização e análise de comentários, menções e respostas de alunos de 6a. série de uma escola pública de Ensino Fundamental do município de Limeira - SP, relacionadas aos significados por eles atribuídos à Tecnologia e ao Programa Pro-álcool.}

\begin{tabular}{|c|c|}
\hline C ategorias de análise & Sub categorias \\
\hline $\begin{aligned}= & \text { Influência do desenvolvimento } \\
& \text { científico-tecnológico na sociedade. }\end{aligned}$ & $\begin{array}{l}\text { = Tecnologia como agente facilitador da vida } \\
\text { cotidiana. } \\
\leqslant \text { D esenvolvimento científico-tecnológico } \\
\text { auxiliando na resolução dos problemas sociais. } \\
\text { ₹ } \text { Desenvolvimento científico-tecnológico } \\
\text { crescimento de ocorrência dos problemas sociais. }\end{array}$ \\
\hline $\begin{aligned} \text { Influência da sociedade na } \\
\text { condução e acompanhamento do } \\
\text { desenvolvimento } \\
\text { científico-tecnológico. }\end{aligned}$ & $\begin{aligned}= & \text { Aspectos sociais envolvidos na produção do } \\
& \text { conhecimento científico-tecnológico } \\
\leqslant & \text { Aspectos econômicos envolvidos na produção } \\
& \text { do conhecimento científico-tecnológico }\end{aligned}$ \\
\hline
\end{tabular}

\section{1-Influência do desenvolvimento científico-tecnológico na sociedade:}

$\mathrm{N}$ esta categoria foram reunidas as respostas ou posicionamentos dos alunos que fize ram menção às influências do desenvolvimento científico-tecnológico na organização da socie dade, ao indicarem situações que alteram hábitos, aspectos de organização do cotidiano ou que apontam para possíveis soluções de problemas que afetam toda a comunidade. É interessante

\footnotetext{
${ }^{6}$ Esse instrumento denominado VOST S consta de vários grupos de afirmações sobre as quais as pessoas precisam relacionar assertivas que se atrelem à afirmação inicial. A pós essa fase são apresentadas justificativas que as pessoas precisam escolher, de acordo com as escol has realizadas na primeira parte do teste. As justificativas apresentadas referem-se aos diferentes aspectos da relação CTS, que se pretende mapear junto às pessoas que terão suas concepções identificadas elou analisadas.

${ }^{7}$ As categorias levantadas pelos autores são: Ciência eTecnol ogia; Influência da Sociedade na C\&T; Influência da C\& T na sociedade; Influência da ciência escolar na sociedade; Características dos cientistas; Construção social do conhecimento científico; Construção social da tecnologia e N atureza do conhecimento científico.
} 
observar que, muitas vezes, os al unos restringem os seus comentários ou posicionamentos que, de alguma forma, espelham suas visões ou idéias sobre esse aspecto da nossa cultura como algo diretamente relacionado com a nossa vida cotidiana, e, nesse caso, são enfatizados por el es como agentes facilitadores do dia-a-dia. Por outro lado, al guns alunos, principalmente com o decorrer do trabalho, parecem apontar para visões que, indicam claramente, uma relação entre a tecnologia e os problemas sociais. N esse caso a tecnologia é vista como um processo que pode contribuir para a resolução dos problemas ou para o aumento da ocorrência e agravamento deles.

\subsection{Tecnologia como agente facilitador da vida cotidiana.}

As respostas agrupadas nesta subcategoria estão sumariadas no Q uadro 3.

\section{Q uadro 3 - C omentários dos alunos (freqüência em números absolutos e percentuais em relação ao total de citações classificadas nesse grupo) de uma 6a série de uma escola pública de Ensino Fundamental do município de Limeira-SP, ao fazerem referências à Tecnologia como agente facilitador da vida cotidiana.}

\begin{tabular}{|l|c|c|}
\hline \multicolumn{1}{|c|}{ Comentários dos alunos } & Número de citações & $\%$ \\
\hline $\begin{array}{l}\text { Por meio das pesquisas poder-se iam desenvolver } \\
\text { instrumentos "facilitadores" da vida cotidiana. }\end{array}$ & 16 & 42,2 \\
\hline $\begin{array}{l}\text { Avanço de condições que melhorariam as mais diversas } \\
\text { atividades cotidianas. }\end{array}$ & 11 & 28,9 \\
\hline $\begin{array}{l}\text { D esenvolvimento de aparelhos eletrodomésticos que } \\
\text { facilitariam o trabalho do cotidiano. }\end{array}$ & 11 & 28,9 \\
\hline
\end{tabular}

O s dados apresentados nesse quadro indicam que a Tecnologia é vista, muitas vezes, como simples sinônimo de máquinas e instrumentos atuais, que teriam função de facilitar a vida das pessoas. 0 computador é o exemplo mais citado pelos alunos, seguido por diferentes exemplos de eletrodomésticos. As citações a seguir exemplificam respostas dadas pelos alunos:

"Para mim a Tecnologia é importante, pois a Tecnologia faz as coisas ficarem mais fáceis. Exemplo: é muito mais fácil ter microondas do que cozinhar em um fogão."

"Tecnologia é uma coisa avançada, serve para as novas coisas como 0 computador é uma Tecnologia."

Com relação às citações envolvendo especificamente o computador, identifica-se que ele é sempre citado como uma Tecnologia avançada. No entanto, como nos lembra Clastres (1982), o julgamento de que existam artefatos tecnológicos mais avançados que outros não é tão simples como observar a data em que foi desenvolvido e/ ou fabricado. Esse jul gamento atre la-se intimamente à configuração geral da sociedade que o planeja e o consome em seu tempo histórico. Por exemplo, as sociedades primitivas não apresentavam técnicas inferiores, quando comparadas com as atuais, no que se refere ao suprimento de suas necessidades, pois elas também conseguiram alcançar seus objetivos sociais, assim como ocorre com a sociedade contemporânea (Clastres, 1982). 
O utra questão levantada pela análise das respostas dos al unos está relacionada com a compreensão da tecnologia como algo avançado, novo, como "coisas da moda". Pelas citações dos alunos, o "tempo tecnológico" não compreenderia o passado, apenas o presente e 0 futuro, este sempre tecnologicamente mais desenvolvido que o tempo atual. $N$ as citações de 11 alunos essa característica, exemplificada nas citações a seguir, encontra-se presente:

"Ela é um modo de sobrevivência avançado; tudo desse ano até o ano 2000 tem muita Tecnologia. Ela serve para as coi sas se tornarem fáceis de se fazer."

"É uma coisa mais avançada, mais nova, com muitas idéias novas e serve pra nós mesmos como por exemplo máquinas e outras coisas que são coisas da moda."

As concepções dos al unos indicam que os julgamentos da sociedade sobre a tecnologia estão restritos às necessidades sociais do espaço - tempo em que ela é praticada e absorvida. Talvez possamos, a partir dessas análises, identificar uma característica de a-historicidade pela qual os alunos concebem a existência e o objetivo da Tecnologia. Provavelmente essa idéia reflita o modo como sempre nos foi apresentado o processo de constituição do conhecimento tecnológico, assim como sua finalidade e interesse, como ressalta Amorim (1995):

Com ingredientes de a-historicidade assim como de neutralidade, a Tecnologia nosé apresentada como mecanismos, processos e resultados, que fazem parte de um processo de domínio e controle da natureza em benefício de todos, não écomprometida com homens interessados em situações concretas. ( p. 39)

\subsection{D esenvolvimento científico-tecnológico auxiliando na resolução dos problemas sociais.}

À medida que as atividades de ensino foram sendo desenvolvidas, novas inter-relações eram levantadas pelos alunos e imediatamente discutidas para uma melhor exploração desses novos elementos. Essa tendência pôde ser claramente observada quando analisamos as referências que os alunos fizeram ao desenvolvimento científico-tecnológico como fator de resolução dos problemas sociais. A maioria delas só foi explicitada quando as últimas atividades estavam sendo desenvolvidas e, mesmo assim, as citações restringiram-se, exclusivamente, à geração de novos empregos pela implementação do Pro-álcool.

D as 17 citações sobre o tema, apenas duas apareceram logo após a discussão das questões relativas à entrevista com pessoas da comunidade, ocorrida no início de agosto. As demais citações apareceram dessa data em diante, com os al unos acrescentando, gradativamente, outros elementos relacionados a essa dimensão analisada. D entre as respostas, o texto de dois alunos referem-se a empregos especial izados:

"Sim, porque poderá empregar as pessoas mais especializadas e mais experientes para
melhorar a cultura de cana-deaçúcar. E melhorar a produção de cana."
"Sim, eles poderão empregar pessoas mais inteligentes para a produção da cana-de
açúcar."

Esse aspecto, qual seja, o de criação de empregos altamente especializados foi citado a partir do estudo dirigido, quando os alunos analisaram as vantagens trazidas por milhões de dólares gastos em pesquisa na área do desenvolvimento científico e tecnológico. Talvez 0 fato represente que pelo menos os dois alunos que teceram tais comentários tenham tomado conhecimento de que apenas com investimentos econômicos significativos em pesquisa poder-seá construir e manter uma classe especializada de trabal hadores. 
No entanto, faltam elementos importantes na análise feitas pelos alunos sobre as possibilidades dessa especialização. $\mathrm{Na}$ análise de Espíndola (1985), por exemplo, essa especialização ocorreria para um pequeno número de pessoas que têm acesso à educação formal e a empregos que delas exigem conhecimentos baseados em habilidades mecânicas e padronizadas: alta atenção (a nova organização de trabal ho informatizada requer vigilância), operação e manutenção de equipamentos eletro-eletrônicos. No entanto, essas habilidades, ainda segundo 0 autor, não estariam acrescentando novos conhecimentos que gerassem reflexões e transformações das ações dos operários. Com a automação a atividade manifesta-se como pertencente à máquina. A atividade do operário torna-se uma abstração. Sua tarefa é a de vigiar a ação das máquinas e a protegêlas das avarias. (Espíndola, 1985, p.86).

Para esses dois alunos, o que garantiria um emprego melhor seria a especialização técnica, pois não transpareceu nos comentários deles uma preocupação com o "porque" mas somente com o "como" das ações. Parece-nos que a queda constante do índice de emprego teve forte influência nas suas idéias, por isso buscaram alternativas com o obje tivo de assegurar melhores colocações com o desenvolvimento de novas habilidades, mesmo que resultem, simplesmente, de operacionalização de artefatos. Essa preocupação espelha as condições de défi cit de emprego caracterizada pelo modelo econômico brasileiro atual.

\section{problemas sociais. \\ 1.3 D esenvolvimento científico-tecnológico aumentando a ocorrência dos}

N essa subcategoria procuramos reunir os posicionamentos ou comentários dos alunos que fizeram referências a aspectos negativos do desenvolvimento científico e tecnológico. Considerando-se os aspectos gerais dos comentários feitos por eles ( $Q$ uadro 4), notamos que não priorizam nenhum problema social em particular, identificando apenas os muito graves e que precisam de atenção maior por parte das autoridades brasileiras.

\section{Q uadro 4 - Comentários dos alunos (freqüência em números absolutos e percentuais em relação ao total de citações classificadas nesse grupo) de uma 6a série de uma escola pública do Ensino Fundamental do município de Limeira SP quando relacionam alguns problemas sociais às transformações tecnológicas advindas da implementação do Pro-álcool.}

\begin{tabular}{|l|c|c|}
\hline \multicolumn{1}{|c|}{ Comentários dos alunos } & Número de citações & $\%$ \\
\hline Aumento das pessoas que passariam fome. & 9 & 32,2 \\
\hline Exploração do trabalho infanto-juvenil. & 9 & 32,2 \\
\hline $\begin{array}{l}\text { Diminuição do emprego, pois as máquinas estariam } \\
\text { fazendo esse mesmo trabalho. }\end{array}$ & 8 & 28,5 \\
\hline $\begin{array}{l}\text { Diminuição das culturas alimentícias acarretando, } \\
\text { crescimento do número de pessoas que passam fome. }\end{array}$ & 2 & 7,1 \\
\hline
\end{tabular}


Embora a maioria dessas considerações façam referências ao aumento de pessoas que passam fome, sem explicitar a relação desse problema com o desenvolvimento científico e tecnológico, tais comentários referem-se a uma questão específica, levantada pelo vídeo "G lobo Repórter", que tratava detal hadamente do projeto Pro-álcool: a diminuição das culturas alimentícias ocasionadas pelo avanço da cultura canavieira. 0 comentário apresentado a seguir exemplifica tal ênfase:

"Bem, a minha opinião é que deveria aumentar os alimentos e não a cana, nós humanos precisamos de alimentos para sobreviver e a cana-deaçúcar nos favorece? 0 álcool para o carro e nos hospitais também é muito utilizado conforme a população vai crescendo e os alimentos vão diminuindo. E aumenta mais o número de misé ria e fome da nossa população. Se a cana diminuísse e os alimentos aumentassem seria bem mehor. Esta éa minha opinião."

O utro fato evidenciado no vídeo do "Globo Repórter", e também mencionado pelos alunos com a mesma força expressiva, é o que remete à exploração do trabalho infantojuvenil realizado nas fazendas produtoras de álcool e açúcar:

"(...)é um problema grave, pois se as crianças são exploradas, elas não têm tempo de estudar e assim será muito difícil de se realizar profissionalmente."

0 comentário acima ainda enfoca o comprometimento do futuro da organização social, uma vez que as crianças e adolescentes que sem a possibilidade de estudar estariam comprometidos do ponto de vista profissional. Para os al unos, o conhecimento adquirido na escola está intimamente ligado à condição para um emprego melhor.

0 aspecto referente ao desemprego causado pela automação da agroindústria canavieira foi evidenciado por vários alunos, que desconsideraram as características positivas dessa automação, como por exemplo, o aumento de rendimento na produção, assim como a melhora da qualidade do ar. Provavelmente 0 alto nível de desemprego no país tenha influenciado os alunos a identificar somente aspectos negativos da automação. Apenas uma aluna citou 0 fato de as máquinas colhedeiras trazerem benefícios ao ambiente, evitando a degradação do solo e a poluição da atmosfera. Essa resposta é dada antes do trabalho realizado com a projeção de um vídeo (citado no Q uadro 1) que faz referência a esse aspecto,

"(...) investindo nas pesquisas podem achar melhores processos com a cana, ou seja, já existe em alguns lugares máquinas que a cana não precisa ser queimada; a máquina já arranca a cana, pois veja, as queimadas poluem o ar que respi ramos, queimam o solo e assim passam para outra área e cada vez mais as nossas terras vão sendo destruídas, mas a máquina já arranca a cana sem precisar ser queimada e assim não polui mais o ambiente e não destrói mais solos."

\section{2-Influência da sociedade na condução e acompanhamento do desenvolvi- mento científico-tecnológico}

Essa categoria orientou a análise das respostas, menções e posicionamentos dos alunos que, de alguma forma, consideraram as influências da sociedade no desenvolvimento da ciência e da tecnologia. 0 objetivo dessa categorização foi o de identificar, na visão dos alunos, a abrangência e intensidade com que a sociedade, por meio dos mais variados instrumentos, consegue participar, desfrutar de, acompanhar e controlar 0 desenvolvimento científico e tecnológico. D ois enfoques foram identificados nos argumentos dos alunos: a influência de al guns aspectos políticos e ideológicos na produção do 
conhecimento científico e tecnológico e a interferência específica de aspectos econômicos nesse processo.

\subsection{Aspectos político-ideológicos envolvidos na produção do conhecimen- to científico-tecnológico}

M esmo considerando a complexidade do processo de produção e desenvolvimento de tecnologia, que envolve as dimensões econômica, política, ideológica e científica (Figueiredo, 1989), buscamos reunir, nesse enfoque, comentários referentes preferencialmente aos aspectos políticos e ideológicos presentes nos processos de desenvolvimento em $C \& T$.

O s alunos, segundo seus comentários ( $Q$ uadro 5), identificam um estreito vínculo entre a responsabilidade do Estado, tendo como representante o governo brasileiro, e o desenvolvimento científico-tecnológico, assim como o entrelaçamento dessas questões com a qualidade do nível educacional.

"(...) M as pena que o presidente não investe nestas possibilidades, em vez dele inves tir no ensino, educação e escolas de ensino científico, ele prefere comprar Tecnologia de fora, ou seja, da Alemanha que possui muita gente interessada em produzi-la.(...)"

\section{Q uadro 5 - C omentários dos alunos (freqüência em números absolutos e} percentuais em relação ao total de citações classificadas nesse grupo) de uma 6a série de uma escola pública do Ensino Fundamental do município de Limeira SP, ao fazerem referências à influência da educação no desenvolvimento científico-tecnológico.

\begin{tabular}{|l|c|c|}
\hline \multicolumn{1}{|c|}{ Comentários dos alunos } & Número de citações & $\%$ \\
\hline $\begin{array}{l}\text { O governo brasileiro não investiria em educação, por isso } \\
\text { não poderia haver grande desenvolvimento tecnológico e } \\
\text { científico. }\end{array}$ & 12 & 80 \\
\hline $\begin{array}{l}\text { Grande parte das aç̃̃es futuras no campo do } \\
\text { desenvolvimento científico e tecnológico estariam nas } \\
\text { mãos dos jovens brasileiros. }\end{array}$ & 3 & 20 \\
\hline
\end{tabular}

Ainda em relação a estas questões políticas, uma aluna chamou a atenção para o fato de ser praticamente impossível a fragmentação entre as diversas dimensões dos aspectos sociais, como desmembrar os fatores econômicos dos políticos ou vice-versa. Como exemplo, a aluna comenta a importância das alianças políticas e da relação destas com os financiamentos para o desenvolvimento de projetos:

"Limeira tem condição, e muita, ainda mais agora com o novo prefe to eleito, que édo mesmo partido do presidente e, assim, pode conseguir muito mais verbas para a cidade. Dinheiro entra e dinheiro sai, e nada eles fazem e nada vemos(...) Se o prefei to, 0 governador do estado e presidente unirem-se, é posśvel existir um IPT em Limeira." 
Alguns alunos fizeram referência à participação do Estado (via governantes) e/ou da ação política da população em projetos de desenvolvimento científicos e tecnológicos ( $Q$ uadro 6). A constatação mais clara, para os alunos, é a referente à falta de ação governamental, de estímulo e/ ou condução de uma constante e permanente política de ação para o desenvolvimento científico e tecnológico.

\section{Q uadro 6 - Comentários dos alunos (freqüência em números absolutos e percentuais em relação ao total de citações classificadas nesse grupo) de uma 6a série de uma escola pública do Ensino Fundamental município de Limeira-SP, ao fazerem referências quando especificam políticas para a condução do desenvolvimento em $C \& T$ realizada pelo Estado brasileiro.}

\begin{tabular}{|l|c|c|}
\hline \multicolumn{1}{|c|}{ Comentários dos alunos } & N úmero de citações & $\%$ \\
\hline $\begin{array}{l}\text { Responsabilidade na condução e/ou orientação das } \\
\text { pesquisas teria que ser exercida pelo G overno, mas isso } \\
\text { não estaria ocorrendo. }\end{array}$ & 8 & 57,2 \\
\hline $\begin{array}{l}\text { Ação direta das pessoas como parte de uma tentativa de } \\
\text { interferência política. }\end{array}$ & 3 & 21,4 \\
\hline $\begin{array}{l}\text { O governo teria e exerceria a orientação e/ou condução } \\
\text { das pesquisas. }\end{array}$ & 2 & 14,3 \\
\hline $\begin{array}{l}\text { Governo apenas iniciaria a atividade de pesquisa científica } \\
\text { que seria realizada visando o bem da população. }\end{array}$ & 1 & 7,1 \\
\hline
\end{tabular}

0 comentário do aluno, transcrito a seguir, mostra, embora reconheça a responsabilidade dos órgãos governamentais, a descrença em relação aos atuais governantes e a crítica, bastante presente na sociedade, em relação a políticos que fazem uso de cargos públicos em benefício próprio:

"(...) o governo, por exemplo, não se interessa por nada, pela Tecnologia, Ciência, nem pela educação, etá preocupado só com o enriquecimento próprio, mas ainda temos esperança nos jovens de hoje, que têm outro pensar, estudam e têm novasidéias, novo jeito, novo pensar, por isso acho que o Brasil tem chances, quem sabe no futuro."

Embora tenhamos pouca tradição em termos de participação direta da sociedade nas questões de planejamento e execução de projetos que incluam, ou não, o processo de desenvolvimento tecnológico, pareceu-nos muito positivo que oito comentários tenham apontado para a necessária vinculação entre propostas políticas e desenvolvimento científico e tecnológico. Esse fato parece indicar que, mesmo vivendo em um ambiente na maioria das vezes hostil à participação nas decisões políticas e econômicas, é possível, por meio do ensino de Ciências, chamar a atenção dos alunos para essas dimensões e promover o interesse, a discussão e a participação da comunidade escolar em questões dessa natureza. A maioria desses episódios de ensino ocorreu após a última atividade, reafirmando que as concepções com maior 
amplitude e inter-relação entre os aspectos econômicos, políticos e sociais do desenvolvimento em $C \& T$ só emergiram após serem trabal hadas em sala de aula.

\subsection{Aspectos econômicos do desenvolvimento científico-tecnológico.}

$\mathrm{N}$ os primeiros momentos de mapeamento das idéias e dos conhecimentos iniciais dos alunos, pudemos notar alguns indícios de compreensão, por parte dos alunos, das interrelações entre os aspectos econômicos e o desenvolvimento científico e tecnológico

Também no início das atividades vinte e cinco alunos elegeram como a principal característica favorável do Projeto o fato de o álcool ser mais barato que a gasolina, indicando uma ligação direta do Pro-álcool com aspectos econômicos. M esmo após as discussões sobre as respostas obtidas nas entrevistas com as pessoas da comunidade, a maioria dos alunos continuou atribuindo o sucesso do álcool combustível ao baixo preço com que chegava ao consumidor.

Um grupo de alunos estabeleceu relações mais específicas entre o desenvolvimento tecnológico e suas conseqüências para o desenvolvimento econômico do país (Q uadro 7), como se identificar a seguir:

"(...) [a Tecnologia serve] Para que o Brasil não fique em desvantagem em relação aos países desenvolvidos."

"Tecnologi a é aquilo que nós chamamos de avanço tecnológico. Serve para desenvolver as coisas ou até mesmo o país."

"U m avanço das coisas e ela serve para ter um melhor uso, um desenvolvimento melhor para o país."

Q uadro 7 - Comentários dos alunos (freqüência em números absolutos e percentuais em relação ao total de citações classificadas nesse grupo) de uma 6a série de uma escola pública do Ensino Fundamental do município de Limeira

SP, quando relacionam o desenvolvimento científico e tecnológico com aspectos econômicos e políticos.

\begin{tabular}{|l|c|c|}
\hline \multicolumn{1}{|c|}{ Comentários dos alunos } & Número de citações & $\%$ \\
\hline $\begin{array}{l}\text { As pessoas preferiram o álcool combustível pelo fato de } \\
\text { ser mais barato que a gasolina. }\end{array}$ & 25 & 83,3 \\
\hline $\begin{array}{l}\text { O Pro-álcool foi abandonado pelo fato das pessoas } \\
\text { perderem a confiança no projeto. }\end{array}$ & 5 & 16,7 \\
\hline
\end{tabular}

No transcorrer das atividades, logo após as férias, quando começamos a enfatizar os aspectos econômicos, políticos e sociais da implementação e do desenvolvimento do Proálcool, os alunos voltaram a ressaltar a importante relação entre desenvolvimento científicotecnológico e verbas. D essa vez, essa característica foi identificada por contraste, isto é, pela influência negativa que a fal ta de investimento trouxe e traz para as pesquisas no Brasil. Alguns 
alunos notaram que, somente com a existência de financiamentos, na sua maioria públicos, alcançaríamos um patamar mais alto no desenvolvimento econômico, para que houvesse melhorias reais para a sociedade.

"No Brasil falta dinherro para desenvol vimento de pesquisa."

"Isso acontece porque as indústrias não incentivam os cientistas a fazerem pesquisas de máquinas e algumas outras coisas que as indústrias utilizam para produzi rem os produtos."

Q uatro alunos aventaram a possibilidade de que, sendo o conhecimento sobre 0 Pro-álcool produzido no próprio país, existiria uma vantagem adicional, visto que tais conhe cimentos poderiam ser traduzidos em ganhos econômicos, reconhecendo, assim, os mecanismos de competição na condução das pesquisas que envolvem os aspectos tecnológicos. A citação abaixo exemplifica esses posicionamentos:

"Sim, porque é uma cultura ecológica [a da cana-de-açúcar] que o Brasil tem que mostrar e essa cultura é conhecida pelo mundo todo, até norte-americanos vieram para ver a produção."

Interessante notar que apenas um aluno explicitou uma característica exclusiva à dimensão econômica de qualquer produção/criação humana: o lucro.

"Na minha opinião se deu 0 avanço da cana-deaçúcar por causa dos seus lucros terem rendido mais, etudo o que rende mais sempretem alguém estudando para que ele renda muito mais do que ele rende agora."

Parece clara para esse aluno a existência de relações entre a seleção e implementação de projetos científicos e tecnológicos e o lucro. Ele também observa que a escolha do objeto de estudo das pesquisas não se relaciona somente com interesses espeć́ficos dos pesquisadores pela simples produção de conhecimento, mas também (ou seria principalmente?) pelos aspectos econômicos ligados à rentabilidade, concebendo, assim, uma atividade científica intensa e intimamente atrelada às dimensões sociais, políticas e econômicas. Ao estabelecer uma relação dessa natureza, qual seja, desenvolvimento científico e tecnológico e os val ores e interesses econômicos, podemos considerar a possibilidade de os alunos estarem detetando uma das características mais marcantes do sistema econômico atual, no qual se observa uma crescente dependência do desenvolvimento da Ciência e da Tecnologia aos ditames e aos interesses do mercado financeiro:

Ora, na medida em que o know-how é aproveitado para aumentar a intensidade da produção e com isso o rendimento ou a mais-valia, o próprio processo produtivo passa a ditar as regras do jogo da produção científica. Fomentam-se aquelas áreas do saber cujas descobertas e inovações possam ser utilizadas direta ou indiretamente na produção. (Freitag,1979, prefácio, p. XVII).

\section{Considerações finais}

A preocupação com o papel do Ensino de Ciências, assim como a sua inter-relação com os valores e interesses que influenciam e são influenciados pelos aspectos socioculturais não são novidades do início deste século. 0 que podemos caracterizar como especificidade do período em que vivemos, principalmente a partir da década de 70 do século XX, são os alertas à intensidade e abrangência da degradação ambiental e 0 agravamento da crise energética. 
Assim, em busca de uma maior articulação entre os objetivos do Ensino de Ciências eas modificações da trama sociocultural atual, é preciso preocuparmo-nos com a incorporação, nas atividades desse ensino, do tratamento de aspectos abrangendo a complexidade das relações CTS.

As possibilidades de considerarmos, em sala de aula, temas ou eventos polêmicos ou controversos, vinculados de alguma forma, a experiências cotidianas da comunidade escolar, têm sido vistas como excelentes oportunidades de responder a demanda premente de abranger a complexidade das relações CTS no Ensino de Ciências. Sem dúvida, essa possibilidade proporciona um elo entre os conteúdos já tradicionalmente trabalhados nas aulas de Ciências e discussões sobre diferentes aspectos da relação Ciência, Tecnologia e Sociedade.

U ma possibilidade muito interessante é encontrada em Watts et al (1997), no relato de trabal hos desenvolvidos em sala de aula, tendo como base um procedimento denominado "event-centred-learning - ECL":

$E C L$ é um procedimento particular para o ensino de tópicos relacionados com as ciênciasnaturais etecnologia em sala deaula. Ele foi sendo delineado como um evento particular, uma ocorrência ou um conjunto de circunstâncias retiradasa partir de exemplos da vida real e utilizados como base para módulos no ensino das ciências. $0 \mathrm{~s}$ eventos de mai or interesse são aqueles ricos em oportunidades curriculares, a partir dos quais um número de questões podem ser abordadas e os módulos desenvolvidos. (p.341)

A escolha de temas específicos, a partir dos quais dar-se-ão as discussões mais amplas com os alunos, é uma maneira, segundo os autores, de tornar o Ensino de C iências mais atrativo, além de possibilitar uma discussão de aspectos não ligados somente aos conhecimentos científicos e tecnológicos presentes. Para que esses objetivos sejam al cançados, os autores propõem um trabal ho que enfatize a resolução de problemas da vida real. $0 \mathrm{ECL}$ tenta retratar uma compreensão mais geral de como a ciência e a tecnologia são influenciadas por fatores sociais, econômicos e políticos, incluindo um entendimento mais amplo sobre a responsabilidade pelos seus desenvolvimentos e resultados. (Watts et al, 1997, p.344)

No caso desta pesquisa, o tema desenvolvido foi o Pro-álcool, por apresentar como característica básica a polêmica em torno de questões sociais e políticas como, por exemplo, 0 modelo sócio-econômico utilizado para seu planejamento e execução, além de abrigar aspectos polêmicos com relação ao conhecimento científico e à aplicação da tecnologia; e por ser muito presente na vida dos alunos.

A sistematização e análise dos dados coletados a partir das atividades desenvolvidas em uma sala de aula de 6 a série do Ensino Fundamental, permitem-nos levantar dois aspectos importantes a serem considerados para atividades dessa natureza.

Um primeiro refere-se ao fato de as relações entre Ciência, Tecnologia e Sociedade já serem apontadas pelos al unos nesse nível de escolaridade, na experiência desenvolvida assim que as atividades de ensino são iniciadas. No entanto, nessas oportunidades, as abordagens são bastante simplistas e ingênuas, estando mais diretamente vinculadas a situações muito imediatas do cotidiano desses alunos.

As discussões sobre o Pro-álcool com alunos da 6a série permitiram identificar, por exemplo, uma concepção de tecnologia segundo a qual o tempo não é compreendido em toda a sua complexidade. A concepção da tecnologia como algo necessariamente moderno faz com que os alunos compreendam-na como uma produção caracteristicamente relacionada ao futuro, ao moderno, desconsiderando o passado como um elemento 
determinante do processo. Fica demarcada, assim, uma visão a-histórica dessa construção humana.

Um segundo aspecto, também muito interessante, é que os alunos conseguiram identificar relações envolvendo aspectos econômicos como influência decisiva nas opções tecnológicas. As percepções dos alunos foram ainda além, pois identificaram que essas opções são definidas por grupos sociais específicos. Essas constatações podem ser verificadas quando, logo no início das atividades, mais da metade dos alunos elegeram como a principal característica produtiva do Pro-álcool o preço do etanol, bem menor que o da gasolina.

$\mathrm{N}$ o entanto, relações mais complexas são explicitadas a partir do momento em que o professor oferece aos al unos material para a análise e reflexão, como pudemos notar durante o desenvolvimento deste trabalho. Q uando o vídeo do "G lobo Repórter" e vários textos em formato de estudo dirigido, foram trabalhados em sala, os alunos identificaram que as interferências não se prendiam especificamente ao aspecto financeiro, mas envolviam também acordos político-ideológicos.

Finalmente, as diferentes etapas que envolveram este trabal ho, desde sua concepção e planejamento, até a análise das ações e reflexões, tanto dos alunos como dos pesquisadores, nos oferecem indicadores bastante ricos quanto aos limites e desafios de propostas como estas. 0 planejamento das atividades e a elaboração dos materiais didáticos a serem utilizados implicam, necessariamente, pesquisas que demandam , na maioria das vezes, tempo de trabalho de que o professor não dispõe. A outra grande dificuldade é a de lidar, em sala de aula, com um tema que envolve, além de conhecimentos biológicos mais objetivos e já tradicionalmente trabalhado nas aulas de Ciências, outros pertencentes a áreas não muito exploradas em atividades de ensino de Ciências $\mathrm{N}$ aturais como, por exemplo, conhecimentos de biotecnologia. U ma outra dimen são do trabalho com a qual o professor não tem muita familiaridade é a discussão de temas envolvendo valores, interesses de grupos sociais específicos e um sistema de crenças que está em jogo.

No entanto, a experiência desenvolvida mostra que, estando o professor interessado na busca de alternativas ao trabalho mais tradicional, que vem sendo desenvolvido em sala de aula e sendo-Ihe oferecidas melhores condições para seu desenvolvimento, como a disponibilidade de tempo e oportunidades para reflexão e elaboração de material didático diversificado, diferentes dimensões relacionadas à Ciência, Tecnologia, Sociedade e Ambiente podem ser incorporadas às aulas.

\section{Referências bibliográficas}

AIKEN HEAD, G.S. e RYAN A.G. The developmente of a new instrument: "Views on Science-Technology-Society" (VOST S). Science Education, v. 76, n. 5, p. 477-491, 1992. AIKEN HEAD, G.S., FLEM M IN G, R.W. and RYAN , A. - High-School Graduates' Beliefs about Science-Technology- Society. I M ethods and Issues in M onitoring Studente Views. Science Education, v. 71, n. 2, p. 145-161, 1987.

AM O RIM , A.C.R. 0 ensino de biologia e as relações entre: Ciência/Tecnologia/Sociedade: 0 que dizem os professores e o currículo do ensino médio? Campinas, SP : Faculdade de Educação, UNICAM P, 1995. (Dissertação, mestrado).

BRASIL (MEC) Parâmetros Curriculares nacionais. ciências naturais. Brasília, Secretaria de Educação Fundamental, 1998. 
CLAST RES, P. A Sociedade contra o Estado. Rio de Janeiro : Francisco Alves, 1982.

ESPÍN D O LA, C. Automação e emprego: uma visão geral. In BEN AKO U CHE, R. (O rg.)

A Informática e o Brasil. São Paulo/ Petrópolis : Polis/Vozes, 1985.

FIGU EIRED 0, V. Produção Social da Tecnologia. São Paulo : Editora Pedagógica e U niversitária, 1989.

FREITAG, B. Prefácio. In M O REL, R.L.M . A política científica no Brasil. T.A. Q ueiroz Editor, 1979.

KRASILCH IK, M . O Professor e o Currículo das Ciências. São Paulo : E.P.U ./EDU SP, 1987. M CCUTCHEON , G . and JU N G, B. Alternative Perspectives on Action Research. Theory into Practice, v. XXIX, n. 3, p. 144-151, 1990.

O BERG ,A. A. and M CCUTCHEON,G. This Issue. Theory into Practice, v. XXIX, n. 3, p. 144-151, 1990.

RO BERTS, D .A. - D eveloping the Concept of "Curriculum Emphasis" in Science Education. Science Education, v. 66, n. 2, p. 243-260, 1982.

SÃO PAU LO (Estado) Secretaria da Educação/C oordenadoria de Estudos e N ormas Pedagógicas. Proposta curricular para o ensino de Ciências e Programas de Saúde - 1 o grau. São Paulo: CEN P, 1991. 66p.

SÃO PAU LO (Estado) Secretaria da Educação/C oordenadoria de Estudos e N ormas Pedagógicas. Proposta curricular para o ensino de Ciências e Programas de Saúde - 1ํo grau. São Paulo: CEN P, 1988. 58p.

SÃO PAU LO, (Estado) Secretaria da Educação. Guia Curricular de Ciências. In: Guias curriculares propostos para as matérias do N úcleo Comum de Ensino de 1ํ G rau. São Paulo:

Cerhupe, 1975. p. 159-182.

TRIVELATO, S.L.F. - Ensino de Ciências e movimento CTS (Ciência/Tecnologia/ Sociedade ). In: ESC O LA DE VERÃO, 3, 1994, Serra N egra. Caderno de Textos... São Paulo : FEU SP, 1994.

WATTS, M. et all. 'Event-centred learning': an approach to teaching science technology and social issues in two countries. International Journal of Science Education, v. 19, n. 3, p. 341-351, 1997.

YAGER, R.E. - Science-Technology-Society as R eform. School Science and M athematics, V. 93, n. 3, p. 145-151, 1993.

\section{Artigo recebido em junho de 2001 e selecionado para publicação em agosto de 2002}

